\title{
Correspondencia de don Alberto Sánchez (I)
}

\author{
José CARlos De Torres*
}

Tras publicar en Anales Cervantinos ${ }^{1}$ las cartas cruzadas que conservamos de don Alberto Sánchez con José María Casasayas, me ha parecido oportuno editar algunas más relativas a temas cervantinos y a diversos temas literarios que salen a colación en el epistolario que mantuvo con numerosos profesores españoles y extranjeros. Reproducimos completas algunas de las cartas y de otras seleccionamos algunos fragmentos que nos han parecido de especial interés, bien por los temas tratados o bien por las personas a las que se dirigen.

Quiero dar las gracias de nuevo a la familia de don Alberto Sánchez, en especial a su hija Marta Sánchez. Asimismo, a la Dra. Alicia Villar, amiga, quien me dio certeros consejos a la hora de publicar el material en los anteriores números de Anales Cervantinos. También a mi buen amigo el Dr. Abraham Madroñal, actual director de la revista. Al actual presidente de la Asociación Dr. José Manuel Lucía Megías y a su predecesor el profesor José Montero, representantes de una nueva etapa de renovación en nuestra Asociación de Cervantistas.

Esta nueva entrega de la correspondencia de don Alberto Sánchez nos recuerda la importancia que siempre han tenido los epistolarios como reconstrucción de datos, circunstancias, personas, acontecimientos que muchas veces se nos escapan en la interpretación de los textos literarios. Ojalá que su lectura nos ilustre acerca de las coyunturas en las que se redactaron estas cartas.

* Consejo Superior de Investigaciones Científicas, CSIC.

1. J. C. de Torres (2010) y (2011). 
Se evocan también lances profesionales que dicen de una etapa muy concreta de nuestra historia cultural.

Decido comenzar con las cartas más afines al tema cervantino, tanto de profesores extranjeros como españoles y según la fecha.

\section{CARTA 1}

\section{Del 15-VIII-1966 de la hispanista italiana Bruna Cinti}

Distinguido señor:

Perdone si acudo a usted sin conocerle personalmente. Soy «lectore» de lengua española en el Instituto Universitario «a Foscari» de Venecia; ya desde meses voy traduciendo al italiano La Galatea de Cervantes que va a ser publicada dentro de poco en su forma italiana.

Quisiera añadir a la traducción una breve nota filológica sobre los criterios que me han guiado en la traducción misma, las dificultades encontradas y otras cosas por el estilo; me parecería bien, además, advertir al lector que se trata de una obra que nunca ha sido traducida al italiano antes de ahora. Esto, al menos, me resulta a mí de los catálogos consultados. Pero, antes de hacer esta declaración, he pensado acudir a su ayuda, rogándole cálidamente -como hago en la presente carta- me conteste, por favor, si a usted mismo le resulte la misma cosa.

De La Galatea he encontrado la traducción al italiano hecha por Ercoliani, pero se trata de La Galatea de Cervantes «traducida» al francés por Florian en el siglo XVIII. He puesto las comillas a «traducida» porque, como usted sabe, se trata de un arreglo muy personal de parte del señor de Florian, que poco o casi nada tiene de Cervantes.

También Luigi Secreti tradujo al italiano esta obrita de Florian. Pero ¿dónde queda ya el grande novelista español?

Espero, confío mucho en su contestación, distinguido señor y amigo. Disponga de mi pobre persona para lo que a usted le haga falta en Venecia mi tierra, ya que seré muy feliz de corresponderle en todo.

Rogándole acepte mis más distinguidos saludos y agradecimientos, queda usted de su afectísima amiga

Bruna Cinti. $^{2}$

Hay la suerte de conservarse copia de la contestación de D. Alberto a la citada profesora italiana, cuyo texto es el siguiente:

2. Cervantes (1968) con introducción, traducción y notas por Bruna Cinti. 


\title{
CARTA 2
}

\author{
Prof. ${ }^{a}$ Bruna Cinti
}

Venecia

Estimada colega:

Al regresar de mis vacaciones veraniegas, me encuentro con su amable carta, de fecha 15 de agosto, que me apresuro a contestar.

Como dice Vd. muy bien, la versión francesa (y bastante empalagosa) de la Galatea por el Sr. Florián tiene poco de original cervantino. Lo que no obsta que sobre esa versión libérrima se hicieran más traducciones a lenguas extranjeras que sobre la de Cervantes, al convertirse el francés en lengua universal de cultura a partir del siglo XVIII. Desde luego, yo no tengo noticias de ninguna traducción de La Galatea de Cervantes al italiano, mientras las hay al francés y al alemán.

Por tanto, le deseo a Vd. buena mano y feliz éxito en la tarea que ha emprendido de verter el mundo pastoril cervantino al hermoso lenguaje de Dante y Sannazaro. Mucho me alegrará el saber que ya lo tiene en las librerías, acreciendo el río caudal de la bibliografía cervantina.

Precisamente en un curso especializado que voy a dar este año sobre las novelas cervantinas, aparte del Quijote, podré hacer alusión a que pronto podrán leer la Galatea en su propio idioma los lectores italianos de Cervantes.

Aprovecha la ocasión para ofrecerse suyo afectísimo servidor y buen amigo

Fdo: Alberto Sánchez

Hay varias cartas de la profesora italiana Donatella Pini Moro desde la Universidà di Padova.

\section{CARTA 3}

Padua, 4 de diciembre de1974

Estimado profesor:

Me es grato enviarle este Quijote italiano -se trata de la conocida traducción de 1933 (Modadori, Bibl. Romantica) por F. Carlesi, ahora nuevamente impresa con introducción de Cesare Segre, y notas, bibliografía y biografía a mi costa- con la esperanza de que pueda conseguir su apreciación y, ¿quizás?, una mención en la valiosa bibliografía que Ud. redacta para Anales Cervantinos. Agradecida por su amable consideración, muy atentamente le saluda

Donatella Moro 
CARTA 4

Del 13 de febrero de 1975

Estimado profesor:

Siento mucho no haber contestado a su atenta del 23 de diciembre. [...].

Muchísimas gracias por la amable acogida que depara a mi primer trabajo cervantino, y también por sus amistosas palabras, que me animan a esperar que un día, quizás en el próximo verano, yo pueda visitar a Ud. personalmente y discutir con Ud. sobre algunos de los miles de problemas que plantea la lectura de Cervantes.

Ahora estoy tratando de analizar la oposición -central en los dos Quijotes - entre el idioma del hidalgo y el de su escudero, pero ¡cuánta es mi ignorancia acerca de la cultura en que, al contrario, Cervantes estaba totalmente hundido! Me refiero al sinfín de libros de caballerías cuyo estilo es recordado tantas veces por don Quijote!

Al Quijote, últimamente, debo también el haber trabado relación con el profesor Meregalli, a quien Ud. nombraba en su carta. Persona muy amable, y además gran conocedor tanto de Cervantes como del cervantismo.

Ante la generosidad y ciencia de ustedes, no es otra mi posición sino la de su humilde y agradecida discípula. Muy atentamente

Donatella Moro

\section{CARTA 5}

De 4 de junio de 1975 (debajo a tinta: Contestada el 28)

Estimado profesor:

Con mucho gusto recibí sus ensayos cervantinos que le agradezco infinitamente.

Además de ser muy útiles por su primaria función de puesta al día bibliográfica e informativa, tienen una claridad ejemplar y nos sitúan magistralmente en dos momentos esenciales de la historia cervantina, sea de crítica sea de textos.

Refiriéndome ahora a su precioso bibliográfico sobre Menéndez Pidal, aprovecho la oportunidad para hacerle una pregunta: el estudio de Menéndez Pidal titulado The genesis of don Quijote (in Cervantes across the centuries. Nueva York. 1947, pp. 32-55) que todavía no he conseguido leer, ¿cómo puede colocarse en el ámbito del cervantismo de Menéndez Pidal? Quizás se trate de la traducción inglesa de la de los ensayos indicados por Ud., o mejor, de una de las «esporádicas menciones...» a las que se refiere Ud. a p. 601.

Perdone mi pesada pregunta, pero es por considerar a Ud. verdaderamente como a mi propio maestro. Muy agradecida, le saludo con afecto

Donatella Moro 
CARTA 6

Del 18 de mayo de 1976

Estimado profesor:

Siento mucho escribirle con tan vergonzoso retraso, sobre todo después de su segundo envío = la separata de su bibliografía cervantina. No encuentro palabras adecuadas para darle bastantemente las gracias por lo que tan generosamente ha escrito sobre el Quijote mondadoriano.

Hace unos días envié, fotocopiada, su extensa nota al profesor Segre, que seguramente va a agradecerle mucho el detenido análisis que Ud. proporciona a su introducción. Pero en este momento me interesa más es hablar de su valioso ensayo machadiano (ipor eso, para leerlo con cuidado, tardé tanto en escribirle!). A este tema que fue objeto de reiterados cursos monográficos y trabajos en el Instituto de Español de Pavía donde estudié con el profesor Caravaggio, le tengo una afición especial. Y en su trabajo encuentro un raro conjunto de rigurosidad informativa, sentido históricocultural y auténtica sensibilidad.

Querido profesor, quizás el verano próximo (1976) nos podamos encontrar, si consigo ir a Madrid con la ocasión del Congreso sobre la Picaresca, seguramente le buscaré.

Sinceramente agradecida, le saluda muy cordialmente

Donatella Moro

Las siguientes cartas son muy interesantes y corresponden al profesor italiano de la Universidad de Venecia, Franco Meregalli, con quien trabajó bastantes años como discípulo el sevillano Carlos Romero, tan ligado a la Asociación de Cervantistas y amigo de José María Casasayas. Por supuesto que el mejor editor de Los trabajos de Persiles y Segismunda. La correspondencia del prof. Meregalli demuestra ser un gran conocedor de la literatura española.

\section{CARTA 7}

Del 3 de octubre de 1974 del prof. Franco Meregalli (hay anotación a máquina de D. Alberto indicando: «Contestada el 12»)

Ilustre y querido colega:

Durante la primera mitad del mes de septiembre he intentado repetidamente ponerme en contacto con Ud. en Medinaceli 4 y llamando por teléfono; pero evidentemente estaba Ud. fuera de Madrid. Estaba completando mis investigaciones para un panorama de la crítica cervantina francesa y española del XIX, continuación de los escritos que le envié. Especialmente me interesaba la parte española (que yo sepa, no existe una tentativa de historizar la crítica cervantina española del XIX, a pesar de la legítima presunción de que en ella se refleja, y de ella hasta cierto punto se puede deducir, el desarrollo de las ideas literarias españolas en general, en este siglo), sobre todo Díaz de Benjumea. 
Encontré a Enrique Canito, mejor dicho le fui a visitar en Ínsula. Le dije que le enviaría un ejemplar de las Obras completas de Cervantes en italiano. Me dijo que le hablaría de ellas.

Espero tener otra ocasión para conocerle a Ud. personalmente. Suyo

Franco Meregalli

\section{CARTA 8 \\ Del 18 de octubre de 1974}

Querido colega y amigo:

Muchas gracias por su carta. Por fin he tomado contacto con Ud.: lo deseaba hacía mucho tiempo.

Naturalmente he leído en los Anales Cervantinos la parte de La estafeta de Urganda con su introducción. Que yo sepa, sólo Ud. y Brüggemann (a quien no he conocido, pero que recuerdo como si fuera un amigo. Hablo de él también en un pequeño trabajo -siempre de historia de la crítica cervantina- que no sé si le envié. Por si acaso le envío una separata) han hablado de Benjumea en los últimos decenios. Como crítico de Cervantes, pero también como personalidad (¿influyó en Unamuno? No lo excluyo. Su escrito sobre la crítica cervantina de Heine, anticipa actitudes de Unamuno) es muy interesante, a pesar de sus hasta demasiado evidentes desaciertos.

En otros tiempos me he ocupado del ensayo de Bodmer sobre el Quijote, que se puede acaso considerar (véase mi Profilo) el primer explícito estudio del Quijote. Es poquísimo conocido. Había empezado una traducción del alemán al español; pero luego me he convencido de que había que ir a Zürich, y nunca he tenido tiempo para ello.

Cordiales saludos. Suyo.

F. Meregalli

PD. Publicaré la continuación del Profilo, referente a la crítica cervatina del XIX en Francia y en España, en las publicaciones de la Fundazione Cini, que tienen una amplia circulación internacional en los más diferentes ambientes (los mismos en que se publicó el Profilo que Ud. conoce). Pero tardará años en salir.

[A la vuelta de la cara de la carta hay el párrafo siguiente de D. Alberto, escrito a máquina: «Escribo el 17-XI, con acuse de recibo de dos publicaciones»].

\section{CARTA 9 \\ Del 4 de diciembre de 1974}

Querido colega y amigo:

Venecia, 4 de diciembre de ' 74

Muchas gracias por su carta del día 17. Yo también he conocido a Farinelli, en 1938 e inmediatamente después de la guerra, en su casa de Turín. Su temperamento «romántico» (se le llamó «Werther de la bibliografía»: 
estupenda definición de su contradictoria personalidad) era muy ajeno al mío; sin embargo, si tuviera que hacer la historia de «mi» hispanismo, Farinelli no dejaría de tener una parte importante, sobre todo en el sentido que también en mi hispanismo hay una fuerte componente de entronque en el romanticismo alemán. Por esto he admirado mucho a Bretrand, a quien no he conocido, y a Brüggemann, a quien tampoco he conocido, y que ha muerto hace poco más de un año.

Este año he desplazado mi atención hacia Calderón, un antiguo culto mío, también relacionado con el romanticismo alemán. Y otra vez tendré que examinar muy cuidadosamente un libro de Brüggeman: Spanisches Theater und deutsche Romantik. Por cierto, es incompresible que obras tan importantes sean poco menos que desconocidas en España.

A propósito de Calderón, estoy estudiando la muchísima bibliografía salida después de mi primer período calderoniano. No veo en ella que se trate un tema que probablemente no tiene gran alcance, en concreto, pero no deja de contestar una pregunta que cualquiera debería ponerse: Calderón tenía 15 años cuando salió el segundo Quijote. Cita a menudo personajes cervantinos; sabemos que escribió un Don Quijote, aunque no lo tenemos; sin duda aprovechó entremeses cervantinos. Pero, en resumidas cuentas, ¿qué importancia tiene Cervantes en la obra de Calderón? Que yo sepa, nadie ha tratado este argumento, un argumento, repito, obvio, tratándose de la presencia del n. 1 de la literatura española en el n. 2 (más que nunca creo que Calderón lo es, a pesar de cierto curioso despego de los españoles).

Muchísimas gracias por su carta, repito otra vez. Mi inclinación me lleva a cierto aislamiento, y sin embrago recibo siempre con alegría noticias de colegas y amigos.

Cordialmente

Franco Meregalli Santa Croce 1337, Venezia

(Nota manuscrita al final de la carta) * Si tiene noticia de algo referente a este tema le agradecería muchísimo me la comunicase.

CARTA 10

Del 11 de diciembre de 1974, todas desde Venecia

Querido colega y amigo:

Venecia, II de diciembre de ' 74

He descubierto que hace algunos días, al hablarle de la eventual presencia de Cervantes en Calderón, he metido la pata, puesto que Ud. es precisamente uno de los pocos que se ha ocupado del problema. Acabo de leer sus Conexiones temáticas. Para decirle la verdad, me convence más la relación Calderón-Zorrilla que la Cervantes-Calderón. Por lo demás, Ud. insinúa más que afirmar la presencia del Rufián en la Devoción. Valbuena Briones (Perspectiva, p. 88) afirma una relación Cerco de Numancia-Sitio de Bredá, que resulta un poco problemática, puesto que el Cerco no se había publicado. Evidentísima es la relación Cueva de Salamanca-Dragoncillo. Muchas citas de obras y personajes cervantinos en Calderón ya las indicó Schmidt hace más de un siglo. 
He buscado en el tomo VI de Anales Cerv. su escrito Reminiscencias..., pero he descubierto que nuestra colección de los Anales es incompleta: falta precisamente el tomo VI. ¿Podría enviarme una separata o una fotocopia? (escrito a mano:) Muchísimas gracias.

Todo queda muy borroso. Lo cierto es que, como Ud. observa (Conexiones, págs. 121 ss.), se trata de dos espíritus muy diferentes. Me sorprende lo lejos de la literatura italiana que está Calderón, en contraste con el profundo italianismo de Cervantes.

Perdone la libertad que me tomo - y disculpe mi gaffe. Le deseo feliz año nuevo. Le saluda su afectísimo

Franco Meregalli

Santa Croce 1337 Venecia

\section{CARTA 11 \\ Del 12 de enero de 1975}

Querido colega y amigo:

Venecia, 12 de enero de 1975

Muchas gracias por sus separatas: he leído con mucho interés la de Anales cervantinos, VI, y he vuelto a examinar el escrito publicado en el Homenaje de Sánchez Escribano por primera vez. Me parece que sobre todo el de Anales Cervantinos hace superfluo otro trabajo. Quedaría el problema de las relaciones entre La muerte y el cap. XI de la II parte, y el de las relaciones entre El dragoncillo y La cueva de Salamanca; pero me escribe E.Wilson que piensa dedicarse a los entremeses y loas de Calderón: frente a tan ilustre y escrupuloso calderonista, me parece lo mejor abandonar también este aspecto del tema. Por lo demás, me convenzo de que, a pesar de las muchas citas (no había pensado en examinar a Ríus; pero ya Schmidt había individuado, hace más de un siglo, muchas alusiones a Cervantes en el teatro calderoniano), el mundo de Cervantes y el Calderón son muy lejanos: Ud. muy acertadamente nota como los dos estilos son de signo diferente. Es sorprendente lo poco de literatura italiana que encontramos en el teatro calderoniano: ya esto nos indica que el mundo de Calderón es muy diferente del de Cervantes, cuyas relaciones con la civilización italiana del Renacimiento son profundas, aún más allá de lo mucho documentable.

Por lo pronto preparo un panorama de la crítica calderoniana actual, que por cierto es más extranjera (particularmente de lengua inglesa, bastante también de alemana) que española.

Otra vez muchísimas gracias. El próximo verano pienso ir a Inglaterra; pero puede ser que pase también por España. En este caso haría otra tentativa para encontrarme con Ud. Feliz año Nuevo. Suyo

Franco Meregalli

[Anotación a máquina de D. Alberto:] Contestada el 20-I-75 con elogio de su separata sobre el Viaje a Turquía. 
CARTA 12

Del 4 de junio de 1975. [Anotación de D. Alberto a máquina «Contestada el 10 de junio»]

Querido colega y amigo:

Venecia, 4 de junio de 1975

Muchísimas gracias por sus dos separa, que recibí hace tiempo. Leí enseguida la referente a estudios cervantinos de M. Pidal; al contrario, no he leído todavía el trabajo sobre Avellaneda, porque se lo he dado enseguida a Romero, que se ocupa específicamente del problema de Avellaneda, y [Carlos] Romero no ha tenido todavía ocasión de devolvérmelo.

Le envío un trabajo mío «Sulla crítica cervantina del romanticismo agli inizi del secolo XX», en italiano, por si le interesa para Anales Cervantinos. $\mathrm{Si}$ le interesa, escríbame (no es necesario que me devuelva el texto: se trata, como nota, de fotocopias; tengo naturalmente el original), para que pueda traducir el texto al español. Creo que el trabajo constituye una contribución provisional, pero apreciable, a la historia de la crítica cervantina. En realidad, anticipa una parte de un perfil histórico de la crítica cervantina en que pienso hace mucho, y que probablemente no llegaré a realizar nunca.

Este año pasaré un mes en Londres, y excepcionalmente no iré a España. Se acercan las vacaciones de verano. Las necesito. Las muertes de colegas y amigos han hecho del año pasado un período más bien deprimente para mí.

Le envié hace algunas semanas una fotocopia de un trabajo sobre Scipione Ammirato y Felipe II, que me parece importante para comprender la actitud de los italianos hacia los españoles en la segunda mitad del siglo XVI. Hay en este escrito también una curiosa alusión a Cervantes, a propósito de La Goleta.

Un cordialísimo recuerdo de su afmo.

Franco Meregalli

Santa Croce 1337. Venecia

[Anotación manuscrita:] * Como de costumbre, pediré a Romero me haga el favor de revisar mi español.

\section{CARTA 13}

Del 22 de junio de 1975. [Anotación de D. Alberto a máquina: Contestada el 28-VI]

Querido colega y amigo:

Venecia, 22 de junio de 1975

Muchísimas gracias por su aceptación de mi escrito sobre crítica cervantina. Me parece perfecto el cambio de título, que quedaría: LA CRÍTICA CERVANTINA DELL' OTTOCENTO IN FRANCIA E IN SPAGNA: acaso menos exacto, pero menos pesado que el original. Le enviaré más tarde una copia en limpio de las páginas más plagadas de correcciones.

Aparte le mando un ejemplar de mi semblanza de Azaña, personalidad trágica y crucial de la historia española de este siglo. Ojalá no vuelvan 
situaciones como aquéllas, de que fue víctima y responsable a la vez, como por lo demás lo somos todos, según nos enseña, entre otros, pero de forma suprema, Calderón.

Si van a Europa central es probable que pasen por Venecia. En este caso esperamos su visita. Mi número telefónico es 27369. Ahora que pasaremos una parte de julio en la sierra, donde tenemos un pisito, y el mes de agosto en Londres. Supongo que en septiembre estaremos en Venecia. De todas formas me haría un gran favor llamándome.

Mi seminario del año próximo tendrá como tema «El teatro español en la crítica de Voltaire a los hermanos Schlegel». Continúo la serie de estudios de literatura española en perspectiva europea.

En estos días estamos preguntando adónde va Italia. El caso es que los comunistas italianos se expresan de la manera más moderada y responsable del mundo, mucho más, por ejemplo, que los socialistas italianos. Claro que se pregunta uno si piensan de verdad lo que dicen, y yo no sabría qué contestar. Como sucede a menudo, las palabras, hechas para comunicar, despistan; a veces significan una cosa, pero la cosa cambia mientras tanto, conservando la misma denominación. Esto, prescindiendo de las intenciones. Durante la interviú televisiva de preparación a las elecciones, un periodista leyó algunas declaraciones de Cunhal, pensando probablemente poner en un apuro a Berlinguer. Berlinguer dijo que L'unità había deplorado dos días antes las declaraciones de Cunhal. (Berlinguer pertenece a una familia noble latifundista sarda; es muy puritano; su esposa va a misa todas las fiestas de guardar.)

Un cordialísimo recuerdo de su amigo

Franco Meregalli

Santa Croce 1337

CARTA 14

Del 11 de julio de 1975

Querido colega y amigo:

Venecia, 11 de julio de 1975

Muchas gracias por su carta del día 28. Me alegro de que le interesen mis trabajos; específicamente considero importante la semblanza de Azaña, personaje que me atrae, y que sin embargo según yo ha cometido grandes errores. Recuerdo de todas formas algo que leí en mi juventud: «Evviva chi si sbaglia in buona fede». La buena fe de Manuel Azaña queda por encima de cualquier sospecha.

Antes de salir de veraneo (iré a la sierra, y después pasaré un mes en Londres) he pensado transcribir las páginas más desordenadas de mi escrito sobre crítica cervantina. Las páginas transcritas encajan exactamente en el texto que le envié, así que es suficiente introducirlas en él, eliminando las anteriores. Espero que de esta forma mi trabajo quede listo para la imprenta. Ojalá salga en 1976: esto significaría esperar un año nada más: poco, según me dice mi experiencia.

Le envidio a Ud. por su magnífico viaje. Mi juvenil deseo de viajar no ha aflojado, a pesar de los años. 
He leído que se ha publicado El gran duque de Gandia, pero tengo que decir que no he leído la obra, y que no me parece particularmente importante publicar obras perdidas de Calderón (no sé si efectivamente lo es la descubierta), puesto que muchas de las seguramente calderonianas se estudian poquísimo. Perdone esta impertinencia... Acabo de redactar un trabajo (destinado al público culto en general, pero con intenciones no sólo divulgativas) sobre La hija de aire: ésta, que es una de las obras maestras del teatro español y universal, ha sido estudiada relativamente muy poco.

Y nada más por lo pronto. Si por casualidad le puedo servir de algo en Londres escríbame, antes del día 20 de agosto, a esta dirección: [...]. Como iré a menudo al British, no me costará nada hacer alguna investigación para Ud.

Le desea felices vacaciones su amigo

F. Meregalli

Santa Croce 1337

\section{CARTA 15}

Del 27 de enero de 1976

Venecia, 27 de enero de 1976

Ilustre y querido colega y amigo:

No quiero dejar sin tempestiva respuesta su carta del día 20, aunque tengo bastante trabajo atrasado, debido a un breve viaje a Bélgica y Alemania en el período de más intensa actividad académica. Recibí ayer su trabajo sobre nuestro entrañable don Manuel Machado, pero no he tenido el tiempo ni el placer de leerlo. Imagínese que en este momento estoy redactando un panorama de la literatura comparada en Italia, en francés, para una revista húngara. Lo demasiado es demasiado.

Muchas gracias por lo que dice de las páginas de F. Ruiz Ramón. Conozco y estimo muchísimo la edición de las Tragedias calderonianas, y no me explico por qué no las he citado en mi ensayo, que se dirige al público italiano. Sin embargo la cito en las líneas (unas diez) de presentación de una traducción mía del alemán al español de un breve escrito sobre La hija del aire de nada menos que Goethe, del que le adjunto una parte, la esencial, que he mandado multicopiar por razones didácticas y que he enviado para la publicación a Segismundo.

Muchísimas gracias por lo que me dice a propósito de la publicación de mi escrito de historia de la crítica. Estoy preparando otro del mismo carácter, que publicaré en nuestros Annali di Ca' Foscari, titulado «Sul teatro spagnolo nella critica da Voltaire ai fratelli Schlegel».

Pienso ir a España en el mes de septiembre, más bien al comienzo, de manera que espero encontrarle a Ud., aunque le llamaré yo por teléfono. En octubre iré a Inglaterra (en agosto al congreso de literaturas comparadas en Hungría, en mayo probablemente otra vez a Alemania): son las últimas (acaso) expresiones de mi Wanderlust, antes de que me eche encima la vejez -también la biológica, puesto que la anagráfica ya la tengo al lado.

Un cordialísimo recuerdo de su amigo 
La correspondencia siguiente es de tema variado e interesante y se ofrece por orden cronológico. Enriquecen la figura de D. Alberto al publicarse cartas de compañeros y conocidos de su profesión profesoral, y además indican cómo lo vieron los que se escribieron con él por distintos motivos.

La primera carta es de un colega y amigo, y es de una época muy temprana, circunstancia a tener en cuenta por la escasez de centros de enseñanza con bibliotecas adecuadas. También creo que es una muestra del conocimiento humanístico de aquellas generaciones de profesores.

\section{CARTA 16}

Instituto de Enseñanza Media (Reus)

31 de enero de 1948

Amigo Sánchez: Bien te agradeceré todo informe que me pueda orientar en el modo de quedarme en Reus, pues hoy por hoy para mí sería una buena solución ante la posibilidad de ir a parar a Astorga, pongo por ejemplo. Ya sabes que en este mundo todo es relativo.

Respecto a tu consulta. En Cataluña a los vencejos se les llama: falzia (s), falzies (pl.). Pero hay muchas variedades comarcales. Así en Reus se las llama: falzilla (s), falzilles (pl.), y es corriente la frase: «va llenger com una falzilla». Un matiz despectivo es el que usan los payeses del Campo de Tarragona, al llamarles falzillots. En el norte de la provincia de Gerona (Olot, San Juan de Las Abadessas) les oí llamar corrientemente falziots. Y creo que por la Cerdaña (Puigcerdà, etc.) les llaman martinets, y menos corrientemente y en grado diminutivo roquerols. Este apartado último no está registrado en mi «sesera» con la precisión de todo lo anterior, sobre todo lo que a la localidad se refiere.

Me dice Apraiz que te diga que posiblemente esta palabra la encuentres en el Atlas Lingüistico de Cataluña de Mossen Griera, con todas sus variedades y localizaciones, pero que te advierta que no puede concederse fe a todo lo que dice, porque en sus encuestas no puso un exceso de escrupulosidad. El roquerol es de montaña; pero también se distingue en la provincia de Gerona el falziot gris, montaraz, del falziot, negro urbano.

Es cuanto sabe decirte este excursionista por encima de las demás cualidades y buen amigo tuyo.

Andrés Bonilla

N.B. Cumplí el jueves 63 «abriles», vulgo ENEROS (sic). Como cada año, al cumplir otro, me echaré a cuestas una excursión de tanteo de fuerzas. El sábado próximo haré una travesía por la Sierra de Prades, de $63 \mathrm{kms}$. 


\title{
CARTA 17
}

La carta siguiente pertenece al profesor D. Américo Castro y es una muestra de la política imperante de entonces y su influencia en tal personalidad de la cultura española.

\section{Sr. D. Alberto Sánchez}

Princeton, N.J. 15 de mayo de 1953

\author{
Madrid
}

Estimado señor:

He recibido y leído su amable reseña de España en su historia, y agradezco que se haya tomado la tarea de analizar lo dicho en ese libro en relación con algunas publicaciones posteriores. Veo que no conoce $\mathrm{V}$. La novedad y las nuevas ni Algunos aspectos del pensar hispano-judio. Documentos, de los que agradan a los historiadores al uso, han confirmado que Luis Vives, Diego de Valera y Santa Teresa (sobre cuyo cristianismo de estilo ya había dicho algo) eran de familia judía. En realidad no hacían falta tales demostraciones, aunque está bien que aparezcan.

Tardará mucho tiempo antes de que se conciba la historia partiendo de la percepción viva de la realidad del hombre. Con todo es muy simpático que en una revista filológica (casi todos los filólogos e historiadores, con hermosas excepciones, siguen sin darse cuenta de qué estoy hablando) salga una larga nota sin malévolas reticencias y sin improperios, que acaban por divertirme.

Le reitero gracias su afmo. s.s.

Américo Castro

P.D. En Cuadernos Americanos (1952) hay otro artículo sobre Juan Ruiz y El scollar de la paloma. No me explico cómo pudo escribir García Gómez eso después de haberle yo leído en París mi artículo de Comparative Literature, ni cómo toleró que al frente de su bella traducción saliesen ciertas frases chabacanas y hasta soeces. Esos son los riesgos del «integralismo» (sic) hispánico.

\section{CARTA 18}

Este escrito es de un profesor hispanista, D. Robert Marras de Francia, y lo motiva la reseña a su libro Cervantes dramaturgo junto a la carta que le envió D. Alberto a París. Creo que es muy interesante.

París, le 3 febrero 1959

\section{Sr. D. Alberto Sánchez}

Distinguido señor mío: recibo su amable carta, y la reseña que Vd. tuvo la bondad de publicar en Anales Cervantinos de mi pequeño Cervantes dramaturgo. En octubre del año pasado, D. José Ares Montes, en la tertulia de Ínsula, me había hablado de la próxima publicación de su artículo sobre mi libro. Le estoy a Vd. muy agradecido por haber dedicado tan 
largo estudio a este libro, que es, a la verdad, mi primer ensayo importante publicado, y por el juicio que a Vd. le merece. Desde luego, en tan pocas páginas como suelen tener los libros de la colección, no podía caber un estudio verdaderamente hondo y muy detenido: por eso tuve que limitarme a los aspectos que me parecían más importantes, dado también que se dirige el libro a lectores aficionados al teatro, pero no a hispanistas.

Sin embargo, quisiera contestar a Vd. sobre algunos puntos de su reseña. Cuando digo que Cervantes no es un dramaturgo genial entiendo que no le fue dado, pero sí a Lope, por ejemplo, crear una forma dramática completamente nueva, en la que pudieran amoldarse obras maestras, y que gustaron al público. Por cierto que la Numancia es un éxito de creación dramática y literaria. Pero la culpa no la tiene Cervantes, ni nadie: la rápida evolución del gusto desde 1580 hasta 1610 poco más o menos hizo que la Numancia representó, a los 10 años de escrita, un ensayo atrasado. Ahora sí encontramos en ella las cualidades de la obra eterna. Y siempre las teorías cervantinas se quedaban atrás del gusto del público.

Otro punto: entiendo por «obras de validez universal» las que, en todos tiempos y bajo los climas se pueden representar sin referencia a la actualidad, a las modas, a la topografía madrileña o toledana, por ejemplo. Cuando digo que son pocas, raras, dichas obras, me refiero más bien a la producción lopesca, en muchas obras de Lope, se incluyen descripciones de calles de Madrid, alusiones a la vida cotidiana de la Corte, etc. Todo esto, si se conserva en una versión a un idioma extranjero, necesita notas al pie de las páginas. Pero ¿en la representación? Al espectador no le es posible acudir a las explicaciones del comentador. Por eso resulta difícil encontrar obras teatrales, como la Numancia, de validez universal, porque plantean problemas eternos y universales. Pero entre las comedias lopescas, ¿cuántas hoy pueden representarse fuera de España sin adaptación o cortes en el texto?

En cuanto a la bibliografía, tuve que quitar muchos títulos, entre los cuales La hija de Agi Morato, por razones de espacio, conservando sólo los más generales y asequibles a un lector no hispanista. Lo sentí mucho, pero el número de páginas había de ser respetado a la fuerza.

De todos modos, otra vez le agradezco su reseña, y me alegro que un cervantista tal como Ud. haya tenido un juicio que tanto me enorgullece acerca de mi ensayo.

Hoy mismo, he dicho al editor que le mande a Vd. un ejemplar de la versión de Numancia que hice con Reybaz: espero que le merecerá una opinión favorable; no creo que hayamos traicionado a Cervantes. Al menos nuestra intención ha sido ser fieles al espíritu de la obra, presentando un texto de posible representación.

Quedo a su disposición por cuanto pueda Vd. necesitar en París, y cuando vaya a Madrid, dentro de unos meses, espero tendré el gusto y honor de encontrarle y saludarle personalmente.

De Vd. affmo. servidor y agradecido amigo

Robert Marrast

Assistant à la Sorbonne

(Letra de D. Alberto) Contestada el 22-II con acuse de recibo de la Numancia. 
CARTA 19

Del profesor D. Fernando Lázaro; hay la suerte de conservarse la carta de 27 de junio de 1959 en la que se alude al libro del citado profesor Marrast y el devenir de sus estudios en España.

Sr. D. Alberto Sánchez

Salamanca 27 de junio de 1959

Madrid

Querido Alberto:

Debes disculparme por la tardanza en contestar a tu carta del 15 de mayo. No estaba entonces en condiciones de contestar a la propuesta de R. Marrast, porque los editores de la coleccioncita estaban deshojando la flor de la continuación. Tras muchos cabildeos familiares ha quedado la hoja del sí. Por tanto puedes comunicar a dicho señor que, con mil amores, recibiríamos la Numancia. No conozco su libro, pero a juzgar por lo que dices en tu reseña, es hombre agudo y con ideas. Esa colección que hace L'Arche en París es estupenda; poseo algunos volúmenes, y voy a encargar este.

Vinieron luego los exámenes, [...].

Excelente tu trabajo sobre las reminiscencias cervantinas en Calderón. Da pena, en nuestra literatura áurea, la falta de alusiones «humanas» entre los grandes. Pequeñas pullas, algún chisme, y para de contar. ¡Qué destino a lo que ocurre en Francia! Hay mucha cicatería en este silencio.

Permaneceré en Salamanca hasta el 20 de julio, para rematar la edición crítica del Buscón. Es un trabajo de chinos; el establecimiento de los criterios de preferencia me ha llevado mucho tiempo; y sólo las variantes suman varios millares.

¿Has viajado para examinar? Nuestro ministerio paga en exámenes lo que no quiere pagar por enseñar.

Te agradezco el trabajo que te has tomado para traer a las filas de Anaya al Sr. Marrast. Efectivamente, tenemos pensado el implicar, como colaboradores, a varios hispanistas extranjeros.

Un fuerte abrazo de tu incondicional

F. Lázaro

(Con letra de Don Alberto:) Contestada el 11 de julio 
CARTA 20

Del profesor D. Juan Luis Alborg (fue quien me enseñó, en el colegio Alemán de Madrid durante el curso preuniversitario de 1954-55, la asignatura de latín...), bien conocido por sus tomos de Historia de la literatura española publicada por Gredos. Es un testimonio más de la actividad de D. Alberto para buscar fuentes que colegas necesitan fuera de Madrid (la Biblioteca Nacional, las del Consejo, etc.). El profesor Alborg estaba por entonces en el Departament of Modern Languages de Padue University.

Sr. D. Alberto Sánchez

19 de enero de 1967

Madrid

Distinguido amigo:

Mi amigo y editor Hipólito Escolar acaba de enviarme la carta que usted le dirigió con fecha 7 del actual a propósito del primer volumen de mi Historia de la Literatura Española y de la separata sobre «Cervantes». Le agradezco muy de veras las generosas palabras que ha tenido usted la gentileza de dedicar a mi modesto trabajo de vulgarización; pero ni siquiera la autoridad de usted consigue envanecerme, porque tengo plena conciencia de las muchas imperfecciones y omisiones que no he podido evitar, y que solo una nueva salida, si hubiera lugar a ello, iré tratando de corregir. Algunos trabajos capitales sobre Cervantes me han sido inasequibles y, concretamente, varios números de los Anales Cervantinos. Esta Universidad - una de las más prestigiosas del país en diversas ingenierías- comienza ahora realmente a ensanchar su visión en el campo de nuestros estudios. Por esto mismo, si sus generosas palabras me permiten tomarme una libertad, yo le agradecería infinitamente que me hiciera enviar relación de las publicaciones e información bibliográfica de ese Instituto a las que sea posible suscribirse o adquirir. Me interesaría muy en particular la totalidad de los Anales, desde su aparición, si están a la venta; yo los adquiriría para mí, si la Universidad no lo hace por tener parte de ellos. Entienda bien; por favor, que no estoy pidiéndole un regalo sino sencillamente una ayuda informativa que para mí sería inapreciable.

Ignoro si usted posee el primer volumen de mi Historia; si no lo tiene, le ruego que se lo pida en mi nombre a Hipólito Escolar. Y lo mismo -si él olvidase hacerlo- el segundo, que ya no puede tardar mucho.

Le ruego acepte el testimonio de mi más cordial amistad

Atentamente le saluda

Juan Luis Alborg

(Con letra de Don Alberto:) Contestada el 11-III-1967. 
CARTA 21

Del profesor español D. Alberto Porqueras, quien fue catedrático en la University of Missouri y que, además de sus libros y artículos, publicó varios trabajos con su colega el profesos D. Joseph L. Laurenti, pertenece a la época en que preparó el Homenaje al profesor Sánchez Escribano.

Sr. D. Alberto Sánchez

9 de mayo de 1967

\section{Madrid}

Querido amigo:

Esta carta «oficial» es para (en nombre también del otro coeditor Carlos Rojas) invitarte «oficialmente» a colaborar en el Homenaje a F. Sánchez Escribano (que debemos mantener «secreto» para producir "sorpresa»). De proyecto, es ya realidad, gracias a una buena subvención de Emory Univ. Lo coeditaré con Emory y Ediciones Alcalá. Tema: libre (aunque claro está que algo cervantino no parecería en este caso muy apropiado). Extensión: 15 a 20 holandesas aproximadamente (puede ser menos). Fecha límite (a ser posible): 1 de octubre 1967. Dirección: o a Rojas (Emory Univ.) o a mí (a partir del 1 de agosto a mis señas oficiales, las del membrete). Espero tu amable confirmación y hasta pronto. Un fuerte abrazo y mil gracias anticipadas

Alberto Porqueras

P.S. 1) Escribano no viene a los coloquios

2) Por correo aparte te envié otro «No sé qué».

(Con letra de Don Alberto:) Contestada el 12.

(Al margen:) Le escribo diciendo si puedo entregar el trabajo de D. Francisco [Maldonado] y el mío a [Juan Manuel] Rozas. (19-X-67).

\section{CARTA 22}

Del catedrático Don Emilio P. Carranza de Madrid y es asimismo interesante al estar relacionada sobre todo con la figura de Blasco Ibáñez. Deja constancia de una fecha no bien conmemorada (la de su nacimiento en 1867), ya que además a la época a la que pertenece el escrito del profesor Carranza, Blasco Ibáñez seguía estando más considerado en el extranjero que en España.

Querido Alberto:

9 de octubre de 1967

He terminado de leer los tres estudios que tuviste la gentileza de dedicarme. Los tres me han interesado mucho. El relato de tu peregrinación por el escenario natural de Shakespeare es interesantísimo y convida a repetirlo. El descubrir el senequismo de Quevedo (así como su relación con Tácito) es empresa muy sugestiva y te ha resultado muy bien. Y dejo en último lugar el comentario sobre «Blasco Ibáñez cervantófilo», que es el que más me ha interesado porque es el que está más relacionado con cosas personales. 
A Blasco no se le perdonan dos cosas: su actuación política -llena de violencias y de valor personal, sin olvidar alguna estridencia- y su triunfo como autor y personaje internacional. España, pobre de recursos materiales y acaso más en la estimación de valores ajenos, sigue poseída por esa envidia, que Unamuno supo ver bien.

$\mathrm{Y}$ ya que te hablo de Unamuno voy a relatarte un episodio que le relaciona precisamente con Blasco y que sirve para definir maravillosamente a ambas figuras:

Don Miguel de Unamuno, exiliado en Francia, visita a Blasco en su residencia parisina de la Avenida de la Ópera. Y mostrando Blasco a Unamuno todo el rebullir de la capital francesa le pregunta:

-Don Miguel, ¿qué puede Ud. echar ahora de menos?

-iGredos!, le contesta el rector.

Termino dándole la enhorabuena por tu excelente trabajo que repara el escándalo de que se deje pasar este 1967 sin apenas ocuparse de un hombre, en cuyos libros tantos extranjeros aprenden nuestra lengua.

Un cordial abrazo

\section{E. P. Carranza.}

P.S. No dejes de pasarme el libro de Prieto. Cítame en cualquier sitio y así tendré el gusto de charlar contigo.

\section{CARTA 23 \\ De Don Alejandro Núñez Alonso también está relacionada con el novelis- ta Blasco Ibáñez y su centenario en España, de cuyo contenido se deduce, de manera inequívoca, el poco eco que tuvo en la sociedad de entonces tal escritor. Se debe destacar que fue la llamada Prensa del Movimiento la que por lo visto se preocupó algo en 1967: los más «liberales» en la cultura por aquella época.}

Sr. D. Alberto Sánchez

Ginebra, 2 de enero de 1968

Madrid

Querido Alberto:

Me dio mucho gusto recibir tu Blasco Ibáñez, cervantófilo, breve pero denso y firme en reconocimiento al gran novelista. Yo nunca perdí de vista la magisterial presencia de Blasco en el panorama de la novela española. Tú lo sabes. Y aún continúa válida y lo será siempre su claridad, amén de sus otras singulares dotes de narrador. Este año -el pasado, centenario de su muerte- tuve la gustosa oportunidad de referirme a él en una encuesta sobre su personalidad, que promovió y publicó la Prensa del Movimiento. Esta encuesta fue una de las escasísimas manifestaciones públicas que se hicieron en recordación del gran novelista -que si aún sigue vivo en la masa actual de lectores- padece la cortina de humo que pretende ocultarlo y borrarlo, que tiende sobre él la intolerancia y el menosprecio de los fantasmones del 98 y los de la monarquía (lo de fantasmones vale a algunos personajes y no a su obra). 
Venimos con frecuencia a Ginebra [...]. Procuraremos, sin embargo, una cita con vosotros a nuestro regreso a Madrid. Muchos recuerdos a Maruchi y besos a las niñas. Para ti un abrazo muy fuerte de

Alejandro.

Se agotó en 10 días Sol de Babilonia, y en la lista de ejemplares para los críticos y amigos quedó cortado en la letra $N$. A nuestro regreso a Madrid os proporcionaré vuestro ejemplar.

Los mejores deseos para 1968.

\section{CARTA 24}

De don José Luis Cano, secretario que fue de la conocida e importante revista literaria Ínsula (situada en la calle Benito Gutiérrez $n .^{\circ} 26$ ) con tertulia en la calle Carmen 9, muestra que D. Alberto estuvo abierto y presente en el mundo literario madrileño de aquellos años. El director de Ínsula fue don Enrique Canito.

Sr. D. Alberto Sánchez

Madrid, 2 de noviembre 1968

Madrid

Querido Alberto:

Quizás recuerdes que hace algún tiempo te rogué -y tú aceptaste-, que nos dieras un artículo para ÍNSULA comentando dos o tres libros recientes sobre Cervantes. Uno de ellos era Cervantes en su época de Francisco Olmos; y otro, creo, el Cervantes de Cabezas. Pero ahora acaba de salir las Reflexiones sobre el Quijote de [Enrique]Moreno Báez, viejo amigo nuestro y colaborador, con el que tenemos el compromiso de hablar de su libro cervantino. ¿Podrías hacer el artículo este mes? En cuanto al espacio, creo que en 5 o 6 holandesas, o quizás menos, tendrías tiempo de hablar de esos dos o tres libros cervantinos.

Ya sabes que ahora Canito, aunque poco, paga algo: 500 por original. Menos da una piedra, como dicen los castizos. No te lo digo porque esto compense le trabajo, sino como nuevo dato o noticia «insular».

Hemos reanudado nuestra tertulia de los miércoles en Carmen 9. A ver si un miércoles te vemos por allí, y charlamos.

Con saludos para tu mujer, recibe un fuerte abrazo de tu buen amigo

José Luis Cano.

Hay las anotaciones autógrafas de D. Alberto:

Contestada el 14-XI

Pedir el tercer libro y ofrecer el artículo para las vacaciones.

En el margen izquierdo con letra de D. Alberto:

1. Don Quijote, ed. Gaos.

2. Moreno Báez.

3. Cabezas.

4. Olmos.

5. Garciasol.

8 folios más medio de notas. 


\section{CARTA 25 \\ Del profesor Edward Riley desde Trinity College en la University of Dublin está relacionada con un libro que se tituló Summa Cervantina, un referente indispensable para saber cómo pensaba una buena parte de la flor y nata del cervantismo internacional de aquellos años.}

Trinity College, 11 de junio 1969

Prof. Alberto Sánchez

Querido amigo:

Muchas gracias por su carta del 3 de junio. Siento que no voy a tener la oportunidad de conocerle en Madrid este año, pero sé bien que en el mes de julio casi todo el mundo se marcha por una razón u otra. Espero que lo pase bien en Middlebroug. Pasé el año 1965-6 en Darmonth College y quedé encantado con Vermont y New Hampshire.

Como va a pasar el verano en los EE.UU. ¿quiere avisar a Avalle Arce de su estancia para que se ponga en contacto con Vd. acerca de su capítulo para nuestra Suma? En este momento está ocupado en trasladarse de Smith College a la Universidad de North Carolina, Chapel Hill, N.C. Desde el 20 de junio su dirección será: Euskaletxea, Route 7, Box 18, Durham N.C. 27707.

Por mi propia parte tengo muy pocas observaciones que hacer sobre su capítulo, que, como ya he dicho, me gustó mucho. Se me ocurre que tal vez la biografía de Pellicer (y quizás la de Quintana) merezca mención entre las primeras, importantes: quiero decir en la bibliografía. He notado alguna omisión de página, año o lugar de publicación en unas pocas referencias a textos (p. ej.: págs. 1, 9, 13, 19). Si puede suplirlos, se lo agradeceremos, pues resultará mucho más fácil para el autor que para los editores. Finalmente, es probable que Bataillon se ocupará más extensivamente de las relaciones con Lope, y Parker o Rodríguez-Moñino de la supuesta edición del Quijote de 1604. En tal caso, ¿le importará que condensemos un poco lo que ha escrito Vd. sobre estas cuestiones?

Tengo que revisar lo dicho sobre el número de las separatas. Támesis acaba de avisarme que habrá 25 (gratis) para cada colaborador.

Muy cordialmente le saluda su buen amigo

Edward Riley. 
CARTA 26

Don Vicente Gaos, comprometido con su monumental edición del Quijote ${ }^{3}$, se escribió con don Alberto para que le facilitara documentación bibliográfica, ya que en Valencia no encontraba toda la que necesitó para el estudio y anotaciones. Recuerdo que estuvo en el Congreso cervantino celebrado en Madrid en 1978, al que asistió José María Casasayas con sus proyectos aún en ciernes. Hay dos cartas.

17 de febrero 1975

Sr. D. Alberto Sánchez

(Letra de Don Alberto:) (Contestada el 22)

Madrid

Mi querido amigo y compañero:

Estoy trabajando en una edición crítica y ampliamente anotada del Quijote. Como es imposible realizar un trabajo así con los medios bibliográficos propios, y en Valencia no hay prácticamente bibliografía cervantina en ninguna biblioteca, tropiezo con grandes dificultades para dar cima a mi labor. Tengo el propósito de pasar temporadas en Madrid (durante las vacaciones de la cátedra) para poder ver libros y artículos de revista inencontrables aquí. Pero, entretanto, he pensado si usted podría ayudarme a resolver el problema que tengo planteado. Concretamente me interesaría obtener (pero no sé cómo) su Iniciación al estudio estilístico del Quijote, a pesar de ser un texto para estudiantes preuniversitarios. También me interesaría saber si había forma de conseguir fotocopias de una serie de artículos aparecidos en los Anales Cervantinos, e incluso en otras revistas. Digo esto porque supongo que no será posible adquirir la colección completa de los Anales -aparte de que de ser posible, sería muy caro. Lo que tal vez sea asequible es suscribirse a los Anales, a partir del tomo X (1971). Una última cosa: recientemente solicité por carta del CSIC un ejemplar de la Bibliografia de la Literatura Hispánica de J. Simón Díaz, tomo VIII, 1970. Pues bien, ni he tenido siquiera contestación. ¿Está agotado? De no estarlo, ¿sería usted tan amable de hacer que se me enviase, contra reembolso?

Le ruego perdone la libertad que me tomo de recurrir a usted, causándole todas estas molestias. Créame que le quedaré muy de veras agradecido por la ayuda que pueda prestarme, y que tanta falta me hace.

En espera de sus gratas noticias, le saluda muy cordialmente su amigo

Vicente Gaos

(Debajo con letra de Don Alberto:)

Secretaría del Menéndez Pelayo

3. Cervantes Saavedra (1987). D. Agustín del Campo hizo posible la terminación por fallecimiento de D. Vicente. 
CARTA 27

1 agosto 1977

(Con letra de D. Alberto:) (Contestada el 7)

Señor D. Alberto Sánchez

Cheste (Valencia)

Querido Alberto:

A mi regreso de todo julio fuera de Valencia me encuentro con tu carta de 15 de julio, y con tus dos separatas. Ante todo me alegro de corazón de saber que superaste felizmente tu operación del ojo derecho. Lo mismo superarás la del izquierdo y volverás a tener tu visión normal.

Tus separatas -cuyo envío te agradezco- no he hecho aún más que verlas por encima (estoy recién llegado, y con mucha correspondencia atrasada); pero ya he visto lo que dices de la posible «gran edición del siglo»-de la que ya he corregido las pruebas del tomo I-. Aunque es predicción hecha con tu conocida generosidad, ojalá no la defraude.

No sé nada de esas conferencias otoñales cervantinas de la Fordham University (de la que fui profesor cuatro años: 1952-56).

¿Podrías decirme algo más de ellas? Tampoco sé nada de M. Criado de Val, a quien escribí ya hace tiempo, manifestándole mi interés por leer una ponencia sobre «Problemas de una edición crítica y anotada del Quijote» en el Congreso internacional sobre Cervantes, que se celebrará en Madrid en julio de 1978, cosa que supe a través de nuestro común amigo Casasayas, con quien pasé en junio un par de días en Mallorca. Me temo que Criado de Val esté molesto conmigo por las objeciones que le hice en mi ensayo sobre el Arcipreste de Hita (publicado en mis Claves de Literatura española). También le hago alguna otra en mi edición del Quijote. Y no solo a Criado de Val, también a otros cervantistas hatzfeldianos y desconzisianos, que arriman demasiado el ascua a la sardina del contrarreformismo de Cervantes: ni tanto (ni tan Américo Castro), ni tan calvo (tan Concilio de Trento). Personalmente estoy más cerca de D. Américo, así que espero de antemano críticas del bando contrarreformista, pero Amicus Plato...

Si se te ocurre venir por Valencia (yo estoy en casa prácticamente todos los días de 8 de la mañana a 2 de la tarde), me encantará que nos veamos y charlemos. Si lo prefieres, puedo acercarme a verte hasta Cheste: en coche es un paseo. Dime qué prefieres.

Hasta tus prontas noticias, un gran abrazo de

Vicente

\section{CARTA 28}

Más tardía de fecha es la carta escrita por el prof. Stanislav Zimic, tan dinámica y sugestiva como él fue.

Febrero 271984

Muy distinguido y querido amigo:

Muchas gracias por su bondadosa carta y por la separata. Su estudio sobre El gran teatro del mundo me parece fascinante y, desde luego, uno 
de los más bellos y significativos que conozco. El método estructuralista utilizado por usted revela todas sus virtudes, porque a la par que se sostiene en lo racional no se desentiende de un muy fino sentimiento. Sus interpretaciones de algunos pasajes, en particular, me parecen brillantísimos, sumamente sugestivos. He recomendado su estudio a mis estudiantes -este semestre enseño un seminario sobre Calderón- y estoy seguro que todo profesor concienzudo tendrá que hacer sobre este genial dramaturgo su «estructura conceptual...», es lectura obligada para los calderonistas.

Acabo de recibir el vol. XX de A.C. Muchas gracias por sus genorosas opiniones acerca de mis trabajos -iyo le debo a Vd. ya tanto! Mi artículo sobre La cueva de Salamanca, ¿saldrá en el vol. XXI? Tuve la impresión que aparecería ya en el vol. XX). ¿Podría pedirle un gran favor? Me gustaría dedicar este estudio a un gran amigo. Si ya no es demasiado tarde, quisiera ponerle esta dedicatoria:

[A mi buen amigo D. Odén Betanzos Palacios].

Muchas gracias. Pronto recibiré las separatas de mis últimos estudios sobre Gil Vicente. Se las enviaré en el deseo de que le resulten interesantes a Vd., me he comprometido a escribir un libro sobre Encina para Taurus, temas de España. Por otra parte, hasta ahora no he tenido suerte en encontrar una editorial que publicara todos mis estudios sobre el teatro de Cervantes o, por lo menos, los 5 publicados por Acta Neophilologica, no muy accesibles al lector en occidente. Sin embargo, no me he rendido todavía.

Espero que podamos vernos en un futuro no muy lejano. Le envío mis mejores deseos y mis más cordiales saludos, con mi siempre mayor agradecimiento, su amigo

Stanislav Zimic

\section{CARTA 29}

\section{Cartas varias}

En la correspondencia de D. Alberto hay varias cartas conservadas de D. Ramón Serrano Vicens, autor de la obra Ruta y patria de don Quijote 4 . La geografía literaria es una parte muy importante de los actuales estudios de Caminería Hispánica ${ }^{5}$, donde se hallan estudios de ingenieros de caminos, historiadores, filólogos, etc. En el tema cervantino a veces se hallan propuestas singulares porque literatura y geografía las enlaza de manera muy personal el autor. Dado que no todo el material es literario, se reproducen los fragmentos relacionados con el tema caminero.

4. Serrano Vicens (1966), con mapas desplegables de las rutas quijotescas según el autor.

5. Consúltense las Actas de los trece congresos internacionales sobre el tema y Criado de Val (2011: I y II). 


\section{CARTA 30}

Sr. D. Alberto Sánchez Sánchez

Madrid

Mislata (Valencia) 3-VI-72

Mi querido amigo:

He recibido su amable carta que de corazón le agradezco y siento no haber sabido su comentario e informe que, según me dice, hizo años atrás a raíz de la publicación de la primera edición. No tuve conocimiento de ello y, repito, que lo siento pues sin duda me hubiera sido útil pues su profundo conocimiento cervantino, sin duda, me habría aportado alguna idea digna de tenerse en cuenta al hacer esta segunda edición.

Como habrá visto, si ya la ha leído, la diferencia sobre la primera es haber corregido algunos puntos de la redacción, aclarado, mediante cortas notas, algún considerando que quedaba algo oscuro, unas ligeras modificaciones, de escasa trascendencia, en la Ruta reflejadas en los croquis dos y tres, tres errores de fecha que, inadvertidamente, se introdujeron en la cronología de la Segunda salida y añadir un Post Scriptum basado en la polémica a través de $A B C$.

Esta puede creer que precisó por mi parte un enorme esfuerzo y deseo de contribuir al esclarecimiento del tema pues cuando escribí la primera réplica solo hacía diez días que había sido intervenido [...]

A su debido tiempo leí íntegro el discurso de D. Luis Ceballos, botánico eminente entre los ingenieros de Montes; y que cito en mi trabajo, y ciertamente me interesó muchísimo este señor al acoplar su estudio a la ruta clásica establecida para Don Quijote; viene a decir que florísticamente no es posible, lo que, de rechazo, favorece mi tesis que había partido de opuesta dirección, o sea tratando de ver si la ruta se podía acoplar a la vegetación que Cervantes va nombrando, junto a las demás cosas que fui considerando.

Bien se me alcanza que la cuestión de la ruta de Montesinos es bastante ardua, pero como Cervantes dice que cuando se dirigen a ella ya llevaban dos jornadas largas, hallándose a casi tres desde el punto de partida, y habiendo caminado en ellas en dirección a Zaragoza, no concuerda con la posibilidad de encaminarse a las inmediaciones de la Lagunas de Ruidera, ni con que el Estudiante, al separarse de ellos, tomara opuesta dirección cuando ellos persistían en proseguir el camino hacia Zaragoza.

La Sima Montesona que propongo no es muy profunda, pero su entrada es vertical, y su fondo, formado por una galería horizontal, tiene un regato que corre por ella.

Mi mal estado de salud cuando encargué esta nueva edición ciertamente, no me consintió un repaso minucioso, limitándome a lo que ya anteriormente tenía anotado en previsión y es por ello que no presté atención, ni caí en cuenta, del error en el nombre de Dorotea. De todas formas su advertencia, que le agradezco muy de veras, me ha permitido que al efectuar la fe de erratas que ha de acompañar a cada ejemplar, pues hay alguna, añada esta corrección que resulta muy oportuna, puesto que aún no se ha distribuido ejemplares sino a unos contados amigos de mi mayor aprecio a quienes advertiré este y los otros leves errores.

Deseando a Vd. y los suyos se hallen bien, sabe tiene siempre todo el aprecio de su buen amigo 


\section{CARTA 31}

Sr. D. Alberto Sánchez, Madrid

Mislata 9 -XII- 72

Mi querido amigo:

Es mi deseo que al llegar estas líneas se encuentre bien y que tenga felices Pascuas y Año Nuevo [...]

Este verano estuve en Santa María de Campo Rus y el cura de allí me dijo que unos días antes había estado allí un Sr. de Madrid que, conociendo mi libro, quería hacer alguna investigación, y en el curso de la misma halló que la víspera de la fecha que yo doy para la $3^{\mathrm{a}}$ salida de don Quijote, había fallecido una de las más importantes señoras del pueblo, y siendo el entierro justamente en la tarde en que (según mi cómputo) salía Don Quijote, es muy comprensible que al estar todo el vecindario en tan importante entierro pudiera salir «sin que persona alguna los viera».

Naturalmente supongo que ello sea mera coincidencia pero no deja de ser interesante.

Reciba una vez más todo el agradecimiento de su siempre buen amigo

Ramón Serrano

Calvo Sotelo, 33

CARTA 32

Mislata (Valencia) 12-XII-74

(Con letra de Don Alberto: Contestado el 15 [14])

Querido amigo:

Mucho desearé que esté bien y todos los de su casa y que tengan unas felices Pascuas y un buen Año Nuevo [...].

Hace poco leí algunas manifestaciones de un cierto señor de Alcázar de San Juan en que propugna ser aquella localidad la patria de Don Quijote, cosa que estimo totalmente impropia, pues de un lado aquella población siempre ha sido crecida, y partiendo de ella no tienen pies ni cabeza ni la ruta ni las distancias y direcciones a otros lugares que señala Cervantes.

Creo tonto pretender hallar una patria real para un personaje también real de carne y hueso, pues Cervantes creó un personaje totalmente imaginado y al que solo pudo dar una patria honoraria.

El que en determinado lugar haya vivido algún hidalgo que llevara en $3^{\circ}$ o $4^{\circ}$ lugar el apellido Quijada o Quesada no es base y, en todo caso, aunque un autor tome como punto de partida un cierto personaje no le obliga a que su lugar haya de ser el imaginado para la acción, pues yo puedo tomar como fundamento un Sr. de Lugo y luego por conveniencia del relato o mía propia establecer la acción en Belchite.

Además todos los «hidalgos» propuestos fueron seres mediocres, incoloros y sin relación alguna con el magnífico ejemplar de Don Quijote.

En fin, repitiéndole mi deseo de que se encuentre bien reciba un cordial saludo de su agradecido y buen amigo 
CARTA 33

Catadau 2-VIII-77

(Con letra de Don Alberto: Contestada el 11)

Sr. D. Alberto Sánchez Sánchez

Cheste

Mi querido amigo:

Por carta recibida de Miguel Bordoy Cerdà, desde Palma de Mallorca, sé que se encuentra ahí convaleciente de una operación oftálmica, de la que deseo muy de veras se restablezca pronto.

Bordoy no sabía que yo le conociera a Vd. y como es un entusiasta de mi estudio Ruta y patria de Don Quijote me indicaba le enviase un ejemplar.

Creo que le envié el libro de la 2. ${ }^{a}$ edición hecha en Zaragoza.

Se halla agotada pues sólo se tiraron dos mil ejemplares, pero si estuviese yo en error dígamelo pues vería forma de conseguir alguno.

Tengo redactado el texto para una posible $3 .^{a}$ edición aunque lo veo problemático, pues, casi sin modificar el texto, he hecho una pequeña corrección de la cronología de la $3 .^{a}$ salida, que adelanto en muy pocas fechas, pues así no sólo coincide con la posible de la octava del Corpus sino con el resto del relato.

Aporto algún nuevo dato, entre ellos el muy significativo de que cuando regresan de Barcelona se encuentran con el lacayo de los Duques que iba allí, y les invita a comer «queso de Tronchón», cosa muy propia si se hallaban en la actual provincia de Teruel en que ese queso ha sido hasta ahora de fama y que no pega lo llevara nadie en la Mancha.

Incluso el extraño apellido «Tosilos» puede ser contracción de Tordesilos, pueblo cercano a Molina de Aragón.

Lo que más me ha sorprendido de mi publicación es que, habiéndolo sido de un tan corto número de ejemplares, haya recibido felicitaciones de países tan diversos como Yugoslavia, Japón, Estados Unidos, Bélgica, Francia, etc. y aun de escritores de mérito como Ramón J. Sender y otros.

Otra cosa curiosa es que el año pasado tuve la paciencia de leerme todas las partidas de bautismo de Santa María del Campo Rus del siglo XVI y no pude hallar ni uno solo de los apellidos que menciona Cervantes, lo que me indujo a creer que éste evitó conscientemente mencionar cualquier apellido de allí, por mejor ocultar la localidad.

De todas formas es de total significación el «Voto a Rus» de Sancho que no es adecuado, ni siquiera, a otros pueblos o comarcas manchegas.

He tenido, asimismo ocasión de constatar como existe una especie de secreto interés en no modificar la actual ruta quijotesca (dicen cervantina) por su impacto económico de algunos lugares.

En Televisión me pusieron escusas y recientemente en el programa «los ríos» a cuyo frente se halla un escritor eximio y que, además estima mucho mi estudio, se pasó todo el rato, hablando del Guadiana, ensalzando los lugares habituales. El sabio botánico e Ingeniero de Montes, Ceballos, en su discurso de ingreso en la Academia de la Lengua ya dijo que la vegetación que menciona Cervantes no es posible en los lugares «oficiales» de la ruta.

En fin yo sigo con mi ilusión de construir una tercera edición pues no tengo en ello interés económico alguno, pero sí muy grande poder hacer 
con ello, mi mejor homenaje a Cervantes, ayudando a esclarecer su inmortal libro.

Yo ando algo medianejo de salud esta temporada y ahora estamos pasando aquí el verano y, posiblemente, a mediados de mes vayamos a la Alcarria.

Un cordial abrazo y recuerdos en su casa de su buen amigo

Ramón Serrano

\section{CARTA 34}

Mislata 18 de octubre de 1977

(Con letra de Don Alberto: Contestada el 15-I-1978)

Sr. D. Alberto Sánchez Sánchez

Madrid

Sentí mucho no haber sido posible este pasado verano habernos visto algún día $[\ldots]$.

En cuanto a la posibilidad de lograr una nueva edición de Ruta y patria de Don Quijote hace luego más conciso y razonable todo el recorrido hasta Barcelona.

También he logrado establecer el lugar en que Cervantes imagina la penitencia de Don Quijote en Sierra Morena. Es en las márgenes del pequeño río (verdadero arroyo) conocido con río Rihuelo (sic), en que no sólo corresponde muy exactamente a la descripción cervantina, sino que, en su márgen, existe un lugar y peñasco tal como lo describe el autor. Este ríoarroyo se haya muy inmediato al río Fresnedas, que ya mencionaba yo antes.

Durante estos años he realizado una serie de experiencias encaminadas a averiguar la posibilidad de árboles que menciona Cervantes en su Don Quijote, y en todos los lugares en que menciona las hayas, las he mandado plantar en el monte $\mathrm{y}$, sin ningún cuidado cultural, han vegetado perfectamente y, algunas ya tienen más de tres metros, lo que creo sirve de elocuente testimonio de que bien pudo haber aquellos árboles en los parajes que Cervantes indica y que, como tantos otros, han desaparecido por acción destructora humana. Igual he hecho con alcornoques donde ahora no hay, pero Cervantes menciona e, igualmente, con resultado favorable.

Por todas estas cosas, más lo fundamental de lo anteriormente razonado, es por lo que de todo corazón desearía esa tercera edición para la que, además tengo un total de 19 fotografías que abarcan todo el recorrido.

Yo, como Vd. sabe, no tengo interés económico alguno en esta labor y gustosamente renunciaría a todo lo posible derecho pues lo único que me interesa es haber laborado por la interpretación del Quijote aunque esta sea, o no, compartida por otras personas. Pero mi veneración hacia la figura de Cervantes me hace pensar que el mejor homenaje que personalmente puedo dedicarle es conseguir la publicación del escrito.

Ello siempre serviría de incentivo a posteriores investigaciones por otros.

Si Vd., como no dudo, tiene interés también en lograr otra edición y dado que a Vd. por sus relaciones y amistades pudiese encontrar un medio 
352 • JOSÉ CARLOS DE TORRES

de lograr el propósito a través de instituciones culturales, oficiales, o no, mucho desearía su valioso apoyo.

Con mis recuerdos en su casa, un cordial saludo con todo el afecto de su siempre incondicional y buen amigo

Ramón Serrano 